\title{
SISTEM INFORMASI PENERIMAAN KARYAWAN BARU PADA PT. EKA BOGAINTI JAKARTA TIMUR
}

\author{
Anugrah Hendri Triyono', Maria Cleopatra ${ }^{2}$, Nunu Kustian ${ }^{3}$ \\ 1,2,3 Universitas Indraprasta PGRI \\ Jl. Raya Tengah No. 80, Kel Gedong, Kec. Pasar Rebo, Jakarta Timur 13760, Jakarta \\ hendritriyono57@gmail.com, mariacleopatra1313@gmail.com, kustiannunu@gmail.com
}

\begin{abstract}
ABSTRAK
Permasalahan dalam proses penerimaan karyawan baru pada PT. Eka Bogainti Jakarta Timur dalam kegiatan penerimaan karyawan baru masih menggunakan sistem manual dalam penerimaan calon karyawan, sehingga masih ada yang mengutamakan saudara sendiri maupun keluarga yang bersangkutan. Tujuan dari penelitian adalah untuk memudahkan bagian penerimaan dalam melakukan proses penerimaan karyawan baru serta mempermudah proses laporan data hasil calon karyawan. Metode penelitian yang digunakan dalam perancangan sistem aplikasi desktop penerimaan karyawan baru berbasis java pada PT. Eka Bogainti Jakarta Timur ini adalah metode Analytical Hierarchy Process (AHP). dengan metode pengambilan data studi lapangan, yaitu melalui pengamatan langsung, wawancara dengan pihak terkait, dan melakukan dokumentasi untuk mendapatkan informasi yang dibutuhkan. Metode pengembangan sistem yang digunakan adalah waterfall. Dalam membangun sistem ini, digunakan alat bantu perancangan sistem yaitu Data Flow Diagram (DFD). Dapat disimpulkan, sistem aplikasi penerimaan karyawan baru ini dapat mempermudah pekerjaan bagian penerimaan karyawan pada PT. Eka Bogainti Jakarta Timur.
\end{abstract}

Kata Kunci: Java, MySQL, Informasi Penerimaan Karyawan, Analytical Hierarchy Process.

\begin{abstract}
Problems in the process of accepting new employees at PT. Eka Bogainti, East Jakarta, in recruiting new employees, still uses a manual system for recruiting prospective employees, so there are still people who prioritize their own relatives and their families. The purpose of the research is to facilitate the admissions department in the process of accepting new employees and to facilitate the process of reporting data on the results of prospective employees. The research method used in designing a Java-based desktop application system for new employee acceptance at PT. Eka Bogainti, East Jakarta, is the Analytical Hierarchy Process (AHP) method. using field study data collection methods, namely through direct observation, interviews with related parties, and conducting documentation to obtain the required information. The system development method used is the waterfall. In building this system, a system design tool is used, namely Data Flow Diagrams (DFD). It can be concluded, this new employee recruitment application system can facilitate the work of the recruitment department at PT. Eka Bogaanti, East Jakarta
\end{abstract}

Key Word: Java, MySQL, Employee Recruitment Information, Analytical Hierarchy Process.

\section{PENDAHULUAN}

Perkembangan akan teknologi informasi dan komunikasi pada masa kini, telah mempermudah manusia untuk menjalankan pekerjaannya sehingga lebih praktis. Banyak organisasi dan instansi, baik pemerintah maupun badan usaha, yang memanfaatkan akan adanya suatu perkembangan teknologi informasi ini. Penggunaan komputer dalam penanganan dan pengolahan data memerlukan suatu prosedur yang tepat, dalam hal ini adalah perangkat lunak aplikasi atau disebut juga program. Pengolahan data yang tepat dan cepat mampu meningkatkan kinerja (Yusuf et al., 2021).
Aplikasi Desktop adalah suatu aplikasi yang berisikan sebuah instruksi standar dari sekumpulan aturan sintaks dan semantik yang digunakan secara khusus untuk mendefinisikan program komputer berbentuk offline atau aplikasi yang dapat dioprasikan secara offline sehingga dapat berjalan sendiri tanpa adanya internet yang terhubung pada komputer (Iskandar et al., 2020)

Pegawai berpotensi adalah aset paling penting untuk mendorong pertumbuhan bisnis, dan sebaliknya pegawai yang kurang berpotensi hanya dapat merusak bisnis. Dalam suatu perusahaan seleksi pegawai baru yang tepat dapat memprediksi kesuksesan bisnis di masa depan (Huda et al., 2020) 
Hendra sebagai pemilik PT Eka Bogainti merasa tertarik untuk membuka restoran ala Jepang di Indonesia, karena pada tahun 1985 konsep tersebut belum ada di Indonesia.

Dalam kegiatan bisnisnya, PT. Eka bogainti belum mempunyai sebuah aplikasi yang dapat mendukung sistem penerimaan calon karyawan baru. Dalam proses penerimaan calon karyawan, bagian penerimaan masih menggunakan sistem manual. Staf harus menyimpan semua data karyawan secara manual dengan menggunakan program Microsoft office di setiap kegiatannya. Oleh karena itu, banyak laporan tumpang tindih dan proses penerimaan kurang efektif. Proses pengolahan data yang belum optimal tersebut perlu dibenahi dengan sistem baru yang terkomputerisasi dan terintegrasi dengan baik agar pengolahan data menjadi lebih efektif dan efisien.

Tujuan dari penelitian ini adalah merancang sistem informasi penerimaan calon karyawan baru untuk memudahkan bagian penerimaan dalam melakukan transaksi penerimaan karyawan serta mempermudah proses laporan hasil calon karyawan.

Menurut teori, SDM adalah faktor kunci dalam pencapaian tujuan bisnis (Dr. Capt. H.M. Thamrin, 2019)

Sementara itu, perancangan adalah proses pengembangan spesifikasi baru berdasarkan rekomendasi hasil analisis sistem (Subhan, 2012). Sistem merupakan sekelompok unsur yang memiliki keterkaitan antara satu dengan yang lainnya,yang memiliki tujuan yang sama dan membangun suatu hal bersama secara struktural guna mencapai tujuaan tertentu yang telah disepakati bersama. (Sutabri, 2012).

Aplikasi merupakan penerapan, menyimpan sesuatu hal, data, permasalahan, pekerjaan kedalam suatu sarana atau media yang dapat digunakan untuk diterapkan menjadi sebuah bentuk yang baru (Hartono, 2014).

Berdasarkan penjelasan di atas, dirancanglah sistem aplikasi desktop penerimaan . Dengan menggunakan sistem aplikasi ini, proses transaksi pemesanan dan pembuatan laporan akan menjadi lebih efektif dan efisien.
Hal ini sesuai dengan hasil penelitian yang menyimpulkan bahwa dengan adanya sistem aplikasi berbasis desktop, pembuatan laporan akan menjadi lebih efektif dan efisien, serta dapat mempermudah karyawan dalam melakukan tugasnya (Ismunandar et al., 2021).

\section{METODE PENELITIAN}

Metode penelitian yang digunakan dalam penelitian yang dilakukan pada PT Eka Bogainti Jakarta Timur menggunakan metode Analytical Hierarchy Process (AHP). Menurut (Sari, 2018) " metode AHP merupakan metode untuk membuat urutan alternatif keputusan dan memilih yang terbaik pada saat pengambil keputusan memiliki beberapa tujuan atau kriteria untuk mengambil keputusan tertentu". Metode AHP akan menyederhanakan masalah yang kompleks menjadi keputusan- keputusan yang lebih kecil sehingga akan mempermudah dalam proses pengambilan keputusan tertentu.

Rancangan kegiatan penelitian dimulai pada bulan April 2021 dengan kunjungan langsung ke lapangan untuk mencatat hal-hal penting mengenai suatu masalah, lalu melakukan wawancara langsung dengan pihak yang bersangkutan yaitu staf pemasaran pada PT. Eka Bogainti.

Dalam membangun sistem aplikasi ini, digunakan alat bantu perancangan sistem yaitu:

Data Flow Diagram (DFD) adalah diagram arus data yang menggunakan simbol-simbol untuk menyajikan entitas, proses, arus data dan penyimpanan yang berkaitan dengan suatu sistem dengan tujuan untuk memberikan indikasi mengenai bagai mana data ditransformasi pada saat data bergerak melalui sistem dan menggambarkan fungsifungsi (dan sub fungsi) yang mentransformasikan aliran data (Kurniawan, 2020).

Bahasa pemrograman yang penulis gunakan adalah java dan database yang digunakan adalah MySQL.

Bahasa Pemrograman Java adalah salah satu dari banyaknya bahasa pemograman yang bisa dijalankan di berbagai sistem operasi 
termasuk juga pada telepon genggam (Nofriadi, 2015).

MySQL merupakan software yang juga termasuk ke dalam sistem manajemen basis data SQL (Database Management System) atau biasa dikenal dengan sebutan DBMS yang multithread dan multi-user (Yudhanto \& Purbayu, 2014).

Model Data Hierarkie merupakan sebuah basis data dengan model data hierarkie terdiri dari sekumpulan record yang dihubungkan dengan satu sama lain melalui tautan berupa pointer yang membentuk suatu struktur hierarkie.(Subandi, S.T. \& Aulia Akhrian Syahidi, S.Pd., 2018)

\section{HASIL DAN PEMBAHASAN Analisa Permasalahan}

Berdasarkan hasil pengamatan, penulis mengidentifikasi permasalahan yang ada di tempat penelitian adalah sebagai berikut.

1. Permasalahan dalam proses penerimaan karyawan baru pada PT. Eka Bogainti Jakarta Timur dalam kegiatan penerimaan karyawan baru masih menggunakan sistem manual dalam penerimaan calon karyawan, sehingga masih ada yang mengutamakan saudara sendiri maupun keluarga yang bersangkutan.

2. Dalam Proses Penerimaan Karyawan Baru masih terbilang kurang efisien dan memakan banyak waktu dalam Proses Penerimaan Calon Karyawan Baru.

3. Meminimalisir penumpukan berkas lamaran yang berakhir tidak terpakai atau sia-sia.

\section{Alternatif Penyelesaian Masalah}

Berdasarkan analisis sistem yang sedang berjalan saat ini penulis melihat kelemahankelemahan dan pokok permasalahan yang terdapat pada sistem informasi penerimaan karyawan baru pada PT. Eka Bogainti, maka penulis dapat menyarankan beberapa alternatif permasalahan yang dapat dicoba, yaitu:

1. Membangun sistem penerimaan yang efektif, efisien dan user friendly.

2. Penulisan skripsi ini bertujuan untuk menghasilkan sebuah aplikasi sistem informasi penerimaan karyawan baru yang nantinya akan digunakan oleh pihak PT Eka Bogainti.

3. Membuat aplikasi sistem informasi penerimaan karyawan baru menggunakan program java netbeans dan xampp.

4. Penerapan dan uji coba program sistem informasi penerimaan karyawan baru untuk membantu mengatasi masalah yang ada di PT Eka Bogainti.

Dirancangnya suatu sistem informasi penerimaan karyawan baru pada PT. Eka Bogainti Jakarta Timur yang terkomputerisasi ini, diharapkan dapat mempermudah proses penerimaan calon karyawan baru.

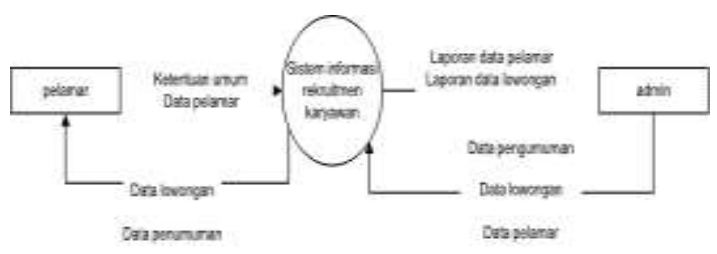

Gambar 1. Diagram Konteks

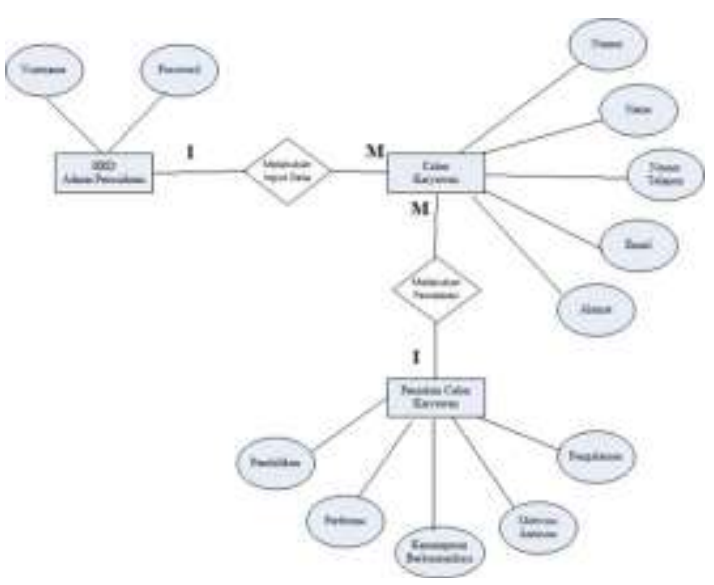

Gambar 2. Entity Relationship Diagram

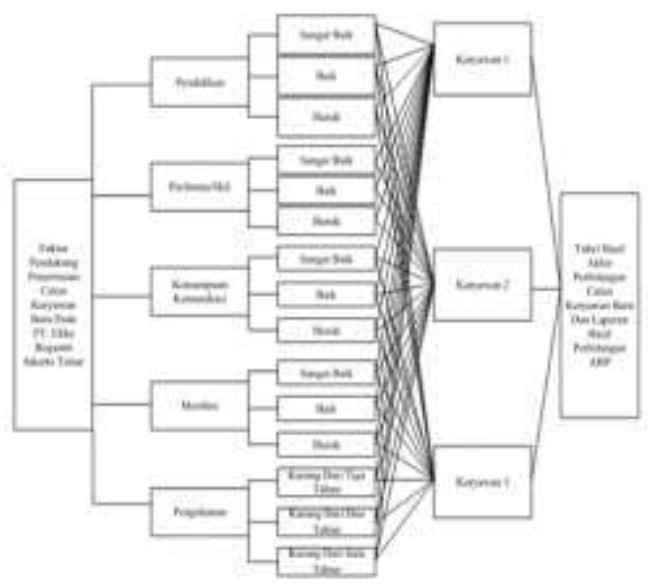

Gambar 3. Skema Hierarkie AHP 


\section{Tampilan Halaman Login}

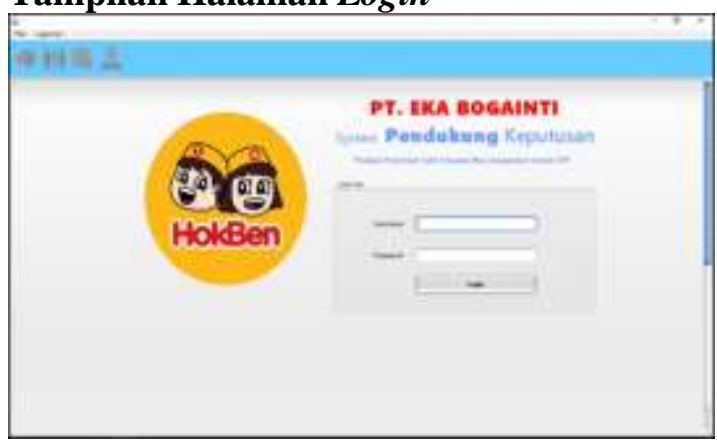

Gambar 3. Tampilan Halaman Login

Pada tampilan awal menjalankan aplikasi ini menampilkan form login. Pengguna diharuskan memasukkan username dan password agar dapat masuk ke halaman menu utama.

\section{Tampilan Menu Utama}

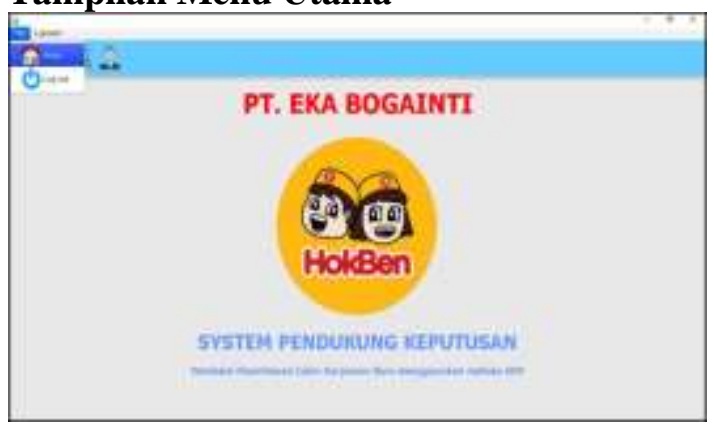

Gambar 4. Tampilan Menu Utama

Pada tampilan ini menampilkan menu utama. Pada layar utama tersedia menu bar yang terdiri dari master data yang digunakan untuk memasukan data kriteria, data nilai kriteria, data detail calon karyawan, data calon karyawan, beranda dan data laporan-laporan.

\section{Tampilan Laporan Menu Kriteria}

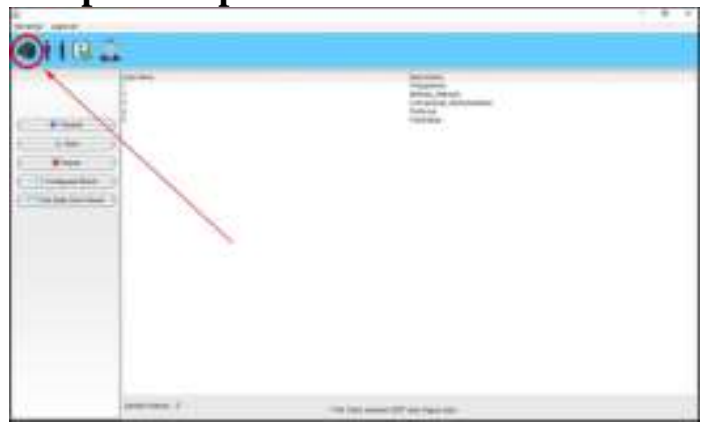

Gambar 5. Tampilan Laporan Menu Kriteria

Pada tampilan ini menampilkan data Menu Kriteria yang dapat ditambahkan dan diubah serta dapat dicetak.
Tampilan Laporan Data Konfigurasi Kriteria

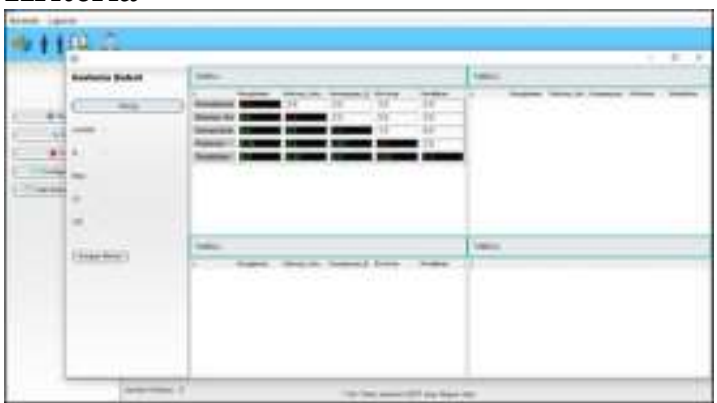

Gambar 6. Tampilan Laporan Data Konfigurasi Kriteria

Pada tampilan ini konfigurasi dan menghitung perbandingan kriteria bobot dengan jumlah kriteria ,menghitung nilai consistency ratio, matrix,jumlah field tabel, consistensi index, dan vector eigen.

\section{Tampilan Laporan Tambah Sub Kriteria}

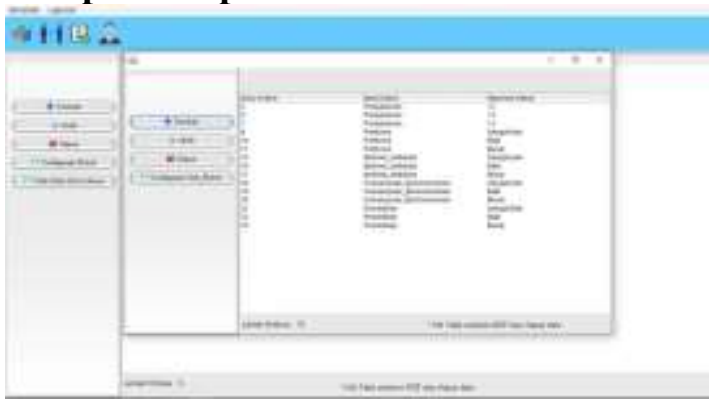

Gambar 7. Tampilan Laporan Tambah Sub Kriteria

Pada tampilan ini menampilkan sub kriteria beserta nilai suib kriteria.

\section{Tampilan Laporan Menambahkan Calon} Karyawan

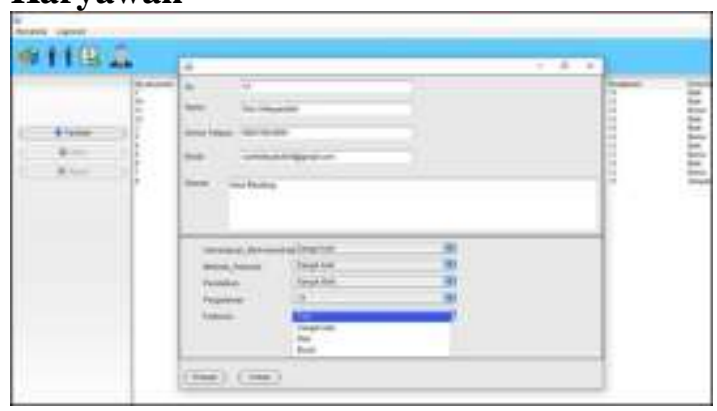

Gambar 8. Tampilan Laporan Menambahkan Calon Karyawan

Pada tampilan ini menampilkan form menambahkan calon karyawan dan juga langsung menilai membandingkan kriteria dan sub kriterianya. 


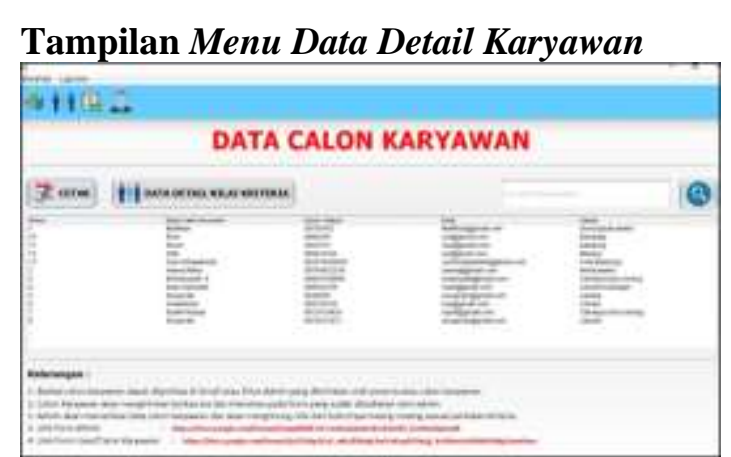

Gambar 9. Tampilan Menu Data Detail Karyawan

Pada tampilan ini menampilkan laporan data detail karyawan dan cetak laporan.

\section{Tampilan Log Out}

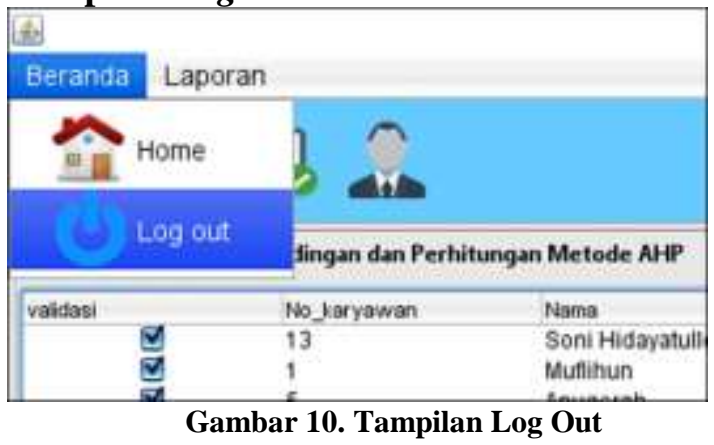

Pada tampilan ini menampilkan tombol keluar aplikasi.

\section{Tampilan Cetak Laporan Data Calon} Karyawan

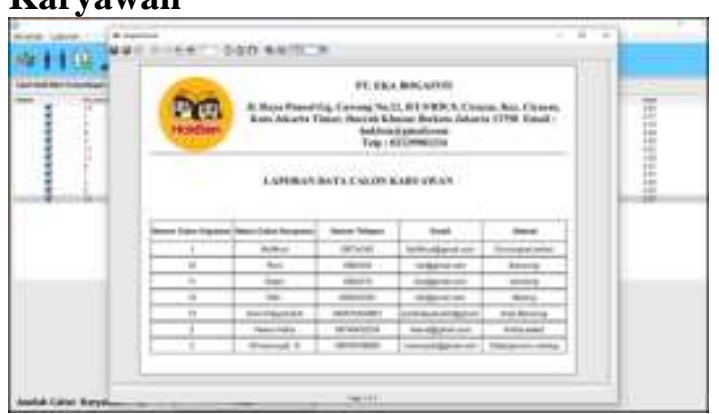

Gambar 11. Tampilan Cetak Laporan Data Calon Karyawan

Pada tampilan ini menampilkan sebuah laporan data calon karyawan yang telah dicetak.
Tampilan Cetak Laporan Data Perhitungan Calon Karyawan

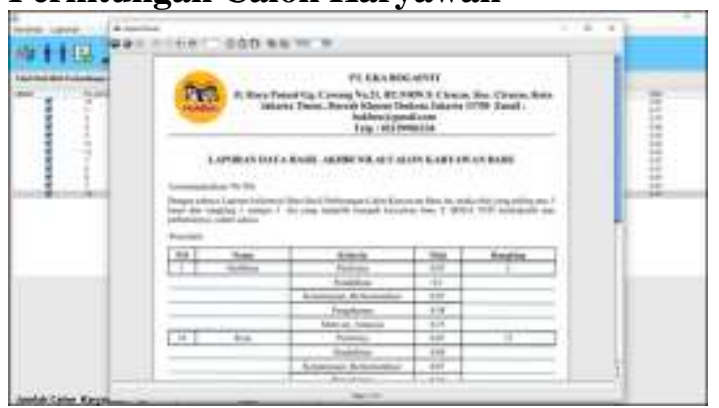

Gambar 12. Tampilan Cetak Laporan Data Perhitungan Calon Karyawan

Pada tampilan ini menampilkan sebuah laporan data perhitungan calon karyawan yang telah dicetak.

\section{Tampilan Cetak Laporan Data Kriteria} Perusahaan

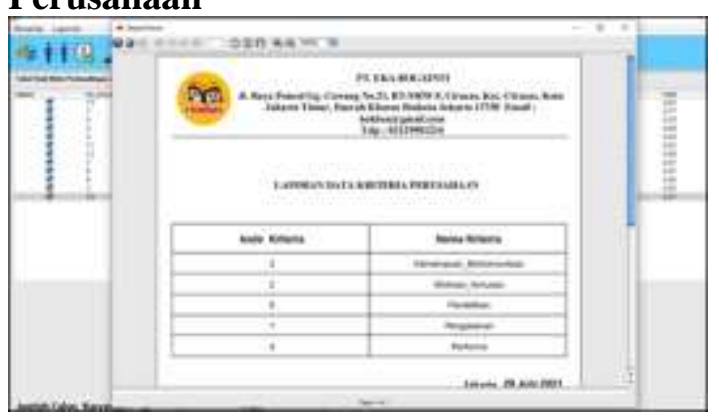

Gambar 13. Tampilan Cetak Laporan Data Kriteria Perusahaan

Pada tampilan ini menampilkan sebuah laporan data kriteria perusahaan yang telah dicetak.

Tampilan Cetak Laporan Nilai Sub Kriteria Calon Karyawan

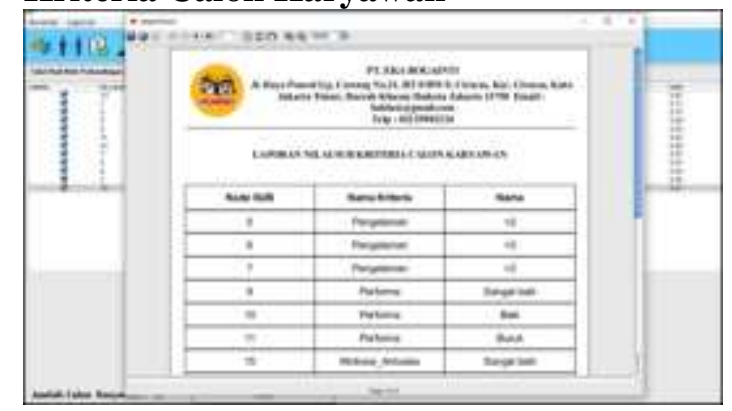

Gambar 14. Tampilan Cetak Laporan Nilai Sub Kriteria Calon Karyawan

Pada tampilan ini menampilkan sebuah laporan data nilai sub kriteria calon karyawan yang telah dicetak. 


\section{Tampilan Cetak Laporan Nilai Sub Prioritas Calon Karyawan}

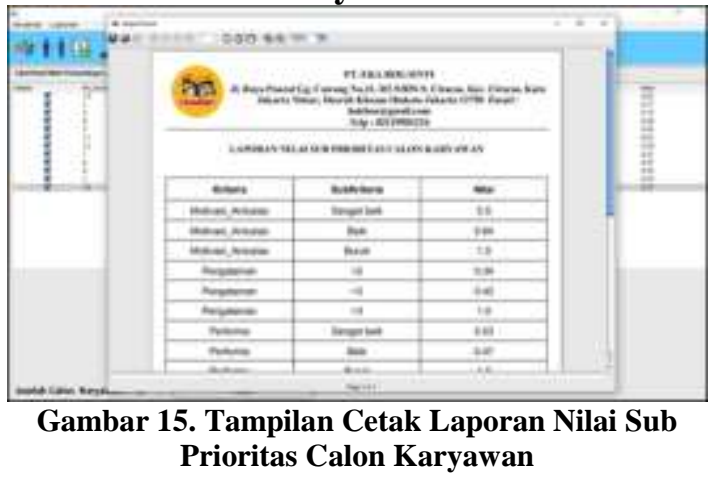

Pada tampilan ini menampilkan sebuah laporan data nilai sub prioritas kriteria calon karyawan yang telah dicetak.

\section{Tampilan Cetak Laporan Nilai Sub Prioritas Kriteria}

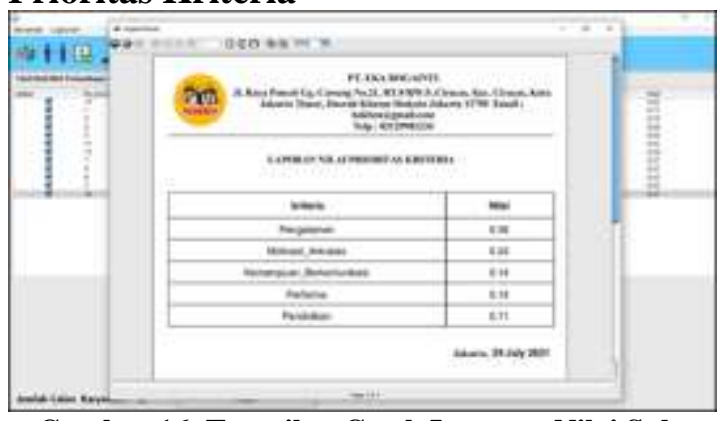

Gambar 16. Tampilan Cetak Laporan Nilai Sub Prioritas Kriteria

Pada tampilan ini menampilkan sebuah laporan data nilai sub prioritas kriteria yang telah dicetak.

\section{Tampilan Cetak Laporan Nilai Bobot Kriteria}

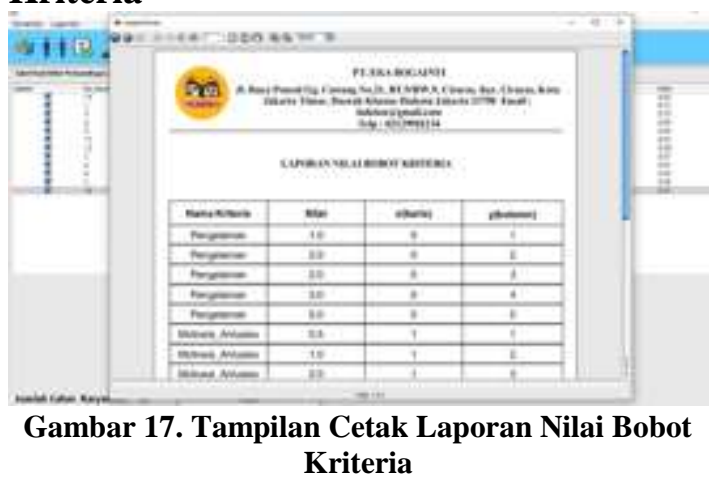

\section{SIMPULAN DAN SARAN}

Peniliti memiliki simpulan sebagai berikut: Sistem informasi penerimaan calon karyawan baru pada PT. Eka Bogainti Jakarta Timur menggunakan sistem pengambilan keputusan dengan metode AHP menjadi lebih efektif dan efisien. Dengan memakai sistem informasi penerimaan calon karyawan baru pada PT. Eka Bogainti dapat membantu admin dalam proses penerimaan karyawan. Sistem informasi penerimaan calon karyawan baru pada PT. Eka Bogainti Jakarta Timur dapat membantu pelamar dalam proses pendaftaran karyawan yang sedang berjalan.

Sejalan dengan sistem yang penulis buat, penulis mengemukakan saran bahwa sistem aplikasi ini masih harus ditingkatkan lagi, baik dari segi fitur maupun pemeliharaannya, agar dapat memenuhi kebutuhan perusahaan ke depannya serta tidak menghambat operasional perusahaan.

Aplikasi pendukung ini supaya bisa dioptimalkan dengan melakukan pengembangan fitur-fitur yang dibutuhkan agar dapat mempermudah pengguna, seperti terintegrasi dengan sistem departemen lain. Aplikasi pendukung ini agar bisa dikembangkan lagi dalam tampilan interfacenya supaya pengguna merasa lebih nyaman, mudah, dan cepat dalam menggunakannya.

Petugas-petugas yang telah ditunjuk perlu melakukan pengawasan secara berkala dalam proses pemeliharaan sistem komputer. Backup data harus selalu dilakukan dalam suatu periode tertentu agar terhindar dari halhal yang tidak diinginkan yang bersifat merugikan.

\section{UCAPAN TERIMAKASIH}

Peneliti mengucapkan terima kasih untuk keluarga besar PT. Eka Bogainti Jakarta Timur yang telah memberikan kesempatan kepada peniliti sehingga peneliti dapat menyelesaikan penelitian ini dengan baik.

\section{DAFTAR PUSTAKA}

Dr. Capt. H.M. Thamrin, M. . (2019). Perencanaan Manajemen Sumber Daya Manusia. CV Budi Utama.

Hartono, J. (2014). Analisis dan Desain Sistem Informasi. Andi Offset.

Huda, A. S., Awangga, R. M., \& Fathonah, R. N. S. (2020). Prediksi Penerimaan Pegawai Baru Dengan Metode Naive bayes. Kreatif Industri Nusantara.

Iskandar, A., Sudirman, A., Safitri, M., Sulaiman, O. krianto, Ramadhani, R., Wahyuni, D., Jamaludin, M. A. K. N. M., \& Simarmata, J. (2020). Aplikasi Pembelajaran Bebasis TIK. 


\begin{abstract}
yayasan kita menulis. https://www.google.co.id/books/edition/Apl ikasi_Pembelajaran_Berbasis_TIK/_LfQD wAAQBAJ?hl=id\&gbpv $=1 \& \mathrm{dq}=$ aplikasi $+\mathrm{d}$ esktop+adalah\&pg=PA95\&printsec $=$ frontc over
\end{abstract}

Ismunandar, A. R. N., Afrizal, T., \& Dwitiyanti, N. (2021). Aplikasi Penjualan Aksesoris Handphone Pada Asia Accessories Hp. Seminar Nasional Riset Dan Inovasi Teknologi (SEMNAS RISTEK), 86-91.

Kurniawan, T. A. (2020). Sistem Informasi Akuntansi Dengan Pendekatan Simulasi. CV Budi Utama.

Nofriadi. (2015). Java Fundamental Dengan Netbeans 8.0.2. Deepublish.

Subandi, S.T., M. K., \& Aulia Akhrian Syahidi, S.Pd., M. (2018). Basis Data: Teori Dan Praktik Menggunakan Microsoft Office Access. Poliban Press.

Subhan, M. (2012). Analisa Perancangan Sistem. Lentera Ilmu Cendekia.

Sutabri, T. (2012). Konsep Sistem Informasi. Andi Offset.

Yudhanto, Y., \& Purbayu, A. (2014). Toko Online Dengan PHP dan My SQL. Elex Media Komputindo.

Yusuf, D., Afrizal, T., \& Budiarto, A. (2021). Perancangan Sistem Aplikasi Pemesanan Lapangan Futsal Berbasis Java Pada Wirabujana Futsal Indramayu. Journal of Information System, Applied, Management, Accounting and Research (JISAMAR), 5(1), 125-131. 